\title{
Analisis faktor - faktor yanng mempengaruhi minat kunjungan ulang wisatawan ke Kebun Binatang Taman Rimba Provinsi Jambi
}

\author{
Mesi Fitriani*; Syaparuddin; Jaya Kusuma Edy \\ Prodi Ekonomi Pembangunan, Fak. Ekonomi dan Bisnis, Universitas Jambi \\ *E-mail korespondensi: messi.einstein2223@yahoo.com
}

\begin{abstract}
The purpose of this study was conducted to determine (1) the development of tourists to the Taman Rimba zoo in Jambi Province (2) to analyze the factors that influence tourist attraction, facilities, accessibility, and service quality on the interest in visiting tourists' return visits. Methods of data collection through observation and distribution of questionnaires to respondents. The data source used is primary data obtained directly from the distribution of questionnaires as many as 157 with 5 question items each. The software used in this research examiner is Statistical Package for The Social Sciences (SPSS). The results of the analysis of this study indicate that simultaneously or together the attractiveness and facilities have a significant or positive effect on the interest in visiting tourists' return visits. Meanwhile, accessibility and service quality has a negative effect on the interest in returning tourists. Partially the average attractiveness, facilities, accessibility, and service quality have a positive or significant effect on the interest in revisiting tourists.
\end{abstract}

Keywords: Tourist attraction, Facilities, Accessibility, Service quality, Interest of return tourists.

\begin{abstract}
Abstrak
Tujuan penelitian ini dilakukan untuk mengetahui (1) Perkembangan wisatawan ke kebun binatang Taman Rimba Provinsi Jambi, (2) Menganalisis faktor - faktor pengaruh daya tarik wisata, fasilitas, aksesibilitas dan kualitas pelayanan terhadap minat kunjungan ulang wisatawan. Metode pengumpulan data dengan cara observasi serta melalukan penyebaran kuesioner kepada responden. Sumber data yang digunakan adalah data primer yang diperoleh langsung dari penyebaran kuesioner sebanyak 157 dengan masing - masing 5 item pertanyaan. Software yang digunakan dalam penguji penelitian ini adalah statistical package for the social sciences (SPSS). Hasil analisis penelitian ini menunjukkan secara simultan atau bersama - sama daya tarik dan fasilitas berpengaruh signifikan atau positif terhadap minat kunjungan ulang wisatawan. Sedangkan aksesibilitas dan kualitas pelayanan berpengaruh negatif terhadap minat kunjungan ulang wisatawan. Secara parsial rata - rata daya tarik, fasilitas, aksesibilitas dan kualitas pelayanan berpengaruh positif atau siginifikan terhadap minat kunjungan ulang wisatawan.
\end{abstract}

\footnotetext{
Kata kunci : Daya tarik wisata, Fasilitas, Aksesibilitas, Kualitas Pelayanan, minat kunjungan ulang wisatawan.
}

\section{PENDAHULUAN}

Tonggak awal pariwisata sesungguhnya telah dimulai sejak dimulainya peradaban manusia itu sendiri, yang ditandai oleh adanya pergerakan manusia yang melakukan ziarah. Namun demikian tonggak-tonggak sejarah dalam pariwisata sebagai 
fenomena modern dapat ditelusuri dari perjalanan Marcopolo (1254-1324) yang telah menjelajahi hampir di seluruh belahan dunia. Sudah berabad-abad lamanya manusia melakukan perjalanan wisata, bahkan sudah ribuan tahun yang silam.

Pariwisata merupakan manifestasi gejala naluri manusia sejak purbakala, yaitu hasrat untuk mengadakan perjalanan. Negara Indonesia memiliki beraneka ragam wisata dan budaya yang terbentang dari sabang sampai marauke, mulai dari tempat wisata dan objek wisata yang kaya akan keindahan wisata alam, taman wisata, taman budaya, dan wisata kulinernya memiliki khas di mana tiap daerahnya memiliki kebudayaan yang berbeda-beda yang melambangkan ciri khas dari daerah tersebut dan banyak turis baik turis domestic maupun mancanegara yang mengagumi keanekaragaman budaya dan wisata di Negara Indonesia.

Defenisi istilah "pariwisata" sangat sulit untuk dirumuskan atau dibatasi tetapi sangat penting peranannya untuk dianalisis. Struktur industri pariwisata dan peranannya dalam pembangunan ekonomi dapat menjadi positif atau negatif, hal ini tergantng pada kriteria yang dipakai (misalnya pertumbuhan ekonomi melawan pemerataan pendapatan), sifat dari industri sendiri dan sifat dari perekonomian lokal Jauh lebih muda membuat analisis tentang pariwisata yang paling besar dan penting adalah pengaruhnya terhadap produk domestik bruto (GDP) di negara-negara yang didominasi oleh pariwisata massal (mass tourism), yaitu di negara-negara yang sangat tergantung pada pariwisata.

Provinsi Jambi terdapat beberapa objek pariwiasata yang salah satunya adalah objek wisata Kebun Binatang Taman Rimba yang merupakan tempat wisata edukasi berbagai jenis fauna yang ada di Indonesia yang merupakan suatu kebanggaan tersendiri bagi masyarakat Kota Jambi yang memiliki objek wisata satu-satunya Kebun Binatang yang ada di Provinsi Jambi. Kebun Binatang Taman Rimba berlokasi di Jalan Sunaryo, tepatnya berada di Kecamatan Jambi Selatan, Kota Jambi, Provinsi Jambi. Taman Rimba ini juga memiliki nilai budaya dari Provinsi Jambi. Maka dari itu objek wisata ini menjadi salah satu tujuan favorit untuk menghabiskan waktu liburan.

Wisata Kebun Binatang Taman Rimba Jambi merupakan salah satu objek wisata andalan yang terdapat di Kota Jambi. Taman ini berada di tengah-tengah kota dan tidak jauh dari Bandar Udara Sulthan Thaha Syaifuddin. Wisata ini merupakan upaya pemerintah untuk menyediakan tempat hiburan yang nyaman bagi masyarakat Jambi. Taman yang didirikan sekitar awal tahun 80an dengan seluas 18 ha menggabungkan dua konsep wisata, yaitu wisata hiburan (bermain) dan Kebun Binatang. Pemprov Jambi menamakan objek wisata ini sebagai Taman Mini dan Taman Rimba Jambi . Selain dapat melihat aneka jenis hewan, wisatawan juga terhibur dengan berbagai macam permainan. Karna itu, objek wisata ini kemudian disebut Taman Mini dan Taman Rimba Jambi.

\section{TINJAUAN PUSTAKA}

\section{Pariwisata (P)}

merupakan konsep yang sangat multidimensional layaknya pengertian wisatawan tidak bisa dihindari bahwa beberapa pengertian pariwisata dipakai oleh praktisi dengan tujuan dan prospektif yang berbeda sesuai tujuan yang ingin dicapai.

\section{Wisatawan $(\mathbf{W})$}

Adalah orang yang mengadakan perjalanan dari tempat kediamannya tanpa menetap di tempat yang didatanginya atau hanya untuk sementara waktu tinggal di tempat yang didatanginya. 


\title{
Daya tarik (DT)
}

Merupakan faktor utama yang menarik wisatawan mengadakan perjalanan mengunjungi suatu tempat, baik suatu tempat primer yang menjadi tujuan utamanya, atau tujuan sekunder yang dikunjungi dalam suatu perjalanan primer karena keinginannya untuk menyaksikan, merasakan, dan menikmati daya tarik tujuan tersebut.

\section{Fasilitas wisata (FW)}

Dapat diartikan suatu sarana dan prasarana yang harus disediakan oleh pengelola untuk kebutuhan wisatawan. Kebutuhan wisatawan tidak hanya menikmati keindahan alam atau keunika objek wisata melainkan memerlukan sarana dan prasarana wisata.

\begin{abstract}
Aksesibilitas (A)
Merupakan faktor penunjang yang memberikan kemudahan bagi wisatawan untuk mencapai objek wisata yang dituju, yang menyangkut kenyamanan, keamanan, dan waktu tempuh.
\end{abstract}

\section{Kualitas pelayanan (KP)}

Menurut Jhon J. Sviokla (2015) merupakan konstribusi keberhasilan suatu perusahaan yang mampu menciptakan suatu persepsi positif dari pelanggan serta mampu mengahsilkan suatu kepuasan dan loyalitas pelanggan.

\section{Minat berkunjung ulang (MBU)}

Didefinisikan sebagai purchase intention yaitu keinginan yang kuat untuk membeli kembali (Fullerton dan Taylor dalam Basiya dan Rozak, 2012). Menurut Miller, Glawter, dan Primban dalam Basiya dan Rozak (2012) mendefinisikan purchase intention adalah keadaan mental seseorang yang mencerminkan rencana untuk melakukan beberapa tindakan dalam jangka waktu tertentu.

\section{METODE}

Data yang digunakan dalam penelitian ini adalah data primer yang didapat dari pusat atau lokasi tujuan penelitian.

\section{Rumus mencari jumlah sampel dalam kuesioner}

Digunakan untuk menjawab tujuan pertama dalam penelitian ini yaitu mengetauhi perkembangan minat kunjungan ulang wisatawan. Dengan rumus model analisis perkembangan sebagai berikut:

\section{Dimana :}

$$
\mathrm{n}=\mathrm{N} /\left(\mathbf{1}+\left(\mathbf{N} \times e^{2}\right)\right)
$$

$\mathrm{n} \quad=$ Jumlah sampel

$\mathrm{N} \quad=$ Jumlah populasi

$e \quad=$ Tingkat kesalahan/ standar error

\section{Teknik pengumpulan data}

Dalam penelitian adalah Kuesioner, kuesioner merupakan teknik pengumpulan data yang dilakukan dengan cara memberi seperangkat pertanyaan atau pernyataan tertulis kepada responden untuk dijawabnya. Penelitian ini menggunakan skala likert yang bisa digunakan untuk mengukur sikap pendapat dan persepsi seseorang terhadap sesuatu (umar, 2002). Dalam penelitian ini responden diminta untuk mengisi kuesioner yang telah dibuat oleh peneliti yang berisi tentang obyek wisata kebun binatang Taman 
Rimba dengan skor (1), sangat tidak setuju (2), tidak setuju (3), netral (4), setuju (5), sangat setuju.

\section{Uji validitas}

Sudjana (2004) Pengertian validitas adalah ketepatan alat penilaian terhadap konsep yang dinilai sehingga betul-betul menilai apa yang harus dinilai. Berikut cara menghitung skor dalam menghitung korelasi antar skor dengan rumus korelasi pearson product moment, (sigit, 2001) :

$$
r_{x y}=\frac{N \sum X Y-\left(\sum X\right)\left(\sum Y\right)}{\sqrt{\left[N \sum X^{2}-\left(\sum X\right)^{2}\right]\left[N \sum Y^{2}-\left(\sum Y\right)^{2}\right]}}
$$

Dimana :

$$
\begin{array}{ll}
\mathrm{R}_{\mathrm{xy}} & \text { : Koefisien korelasi pearson product moment } \\
\mathrm{N} & \text { : Jumlah sampel } \\
\sum_{\mathrm{xy}} & \text { : Jumlaj perkalian skor item dengan skor total } \\
\sum_{\mathrm{x}} & \text { : Jumlah skor } \\
\sum_{\mathrm{y}} \mathrm{:} \text { Jumlah skor total } \\
\sum_{\mathrm{x}}^{2} & \text { : Jumlah kuadrat skor item } \\
\sum_{\mathrm{y}}{ }^{2} & \text { : Jumlah kuadrat skor total }
\end{array}
$$

\section{Uji reabilitas}

Adalah serangkaian pengukuran atau serangkaian alat ukur yang memiliki konsistensi jika pengukuran yang dilakukan dengan alat ukur itu dilakukan secara berulang. Reliabilitas tes, merupakan tingkat konsistensi suatu tes, adalah sejauh mana tes dapat dipercaya untuk menghasilkan skor yang konsisten, relatif tidak berubah meskipun diteskan pada situasi yang berbeda menurut (Sugiono, 2005). dalam penelitian ini dengan metode alpha cronbach, secara manual dengan rumus alpha sebagai berikut :

$$
r=\left[\frac{k}{(k-1)}\right]\left[1-\frac{\sum \sigma_{b}^{2}}{\sigma_{t}^{2}}\right]
$$

Dimana :

$\mathrm{r} \quad$ : Reliabelitas instrumen

$\mathrm{k} \quad$ : Banyaknya butir pertanyaan atau banyaknya soal

$\begin{array}{ll}\sum_{\substack{\alpha \\ t}}^{\alpha} b^{2} & : \text { Jumlah varian butir } \\ & : \text { Varian total }\end{array}$

\section{Uji analisis regresi linear berganda}

Untuk menganalisis pengaruh variabel independen terhadap variabel dependen alat analisis yang digunakan adalah analisis linaer berganda. Menurut Sugiyono (2014) Analisis regresi linier berganda bermaksud meramalkan bagaimana keadaan (naik turunnya) variabel dependen (kriterium), bila dua atau lebih variabel independen sebagai faktor prediator dimanipulasi (dinaik turunkan nilainya).

$$
Y=a+b_{1} X_{1}+b_{2} X_{2}+b_{3} X_{3}+b_{4} X_{4} \ldots \ldots \ldots \ldots . . . . .+b_{k} X_{k}
$$

Dimana :

Y : Variabel bebas yang mempengaruhi wisatawan berkunjung kembali

A : Harga konstan ( harga Y bila $\mathrm{X}=0$ )

$\mathrm{X}_{1} \quad$ : Variabel daya tarik wisata 
$\mathrm{X}_{2} \quad$ : Variabel fasilitas

$\mathrm{X}_{3} \quad$ : Variabel aksesibilitas

$\mathrm{X}_{4} \quad$ : Variabel kualitas pelayanan

$b_{1} b_{2} b_{3} b_{4}:$ menunjukan angkat peningkatan/penurunan variabel dependen.

\section{Uji Normalitas}

Menurut Imam Ghozali (2013) tujuan dari uji normalitas adalah sebagai berikut : Uji normalitas bertujuan untuk mengetahui apakah masing-masing variabel berdistribusi normal atau tidak. Untuk menguji normalitas suatu data dapat digunakan tes normalistas kolmogorov-Smirnov. Data bisa dikatakan terdistribusi normal apabila signifikan masing-masing variabel >0,05, menurut ghozali (2009) dilakukan uji sebagai berikut :

$\mathrm{H}_{0}$ : Residual terdistribusi normal

$\mathrm{H}_{\mathrm{a}}$ : Residual tidak terdistribusi normal.

\section{Uji Multikoliniaritas}

Uji multikoliniaritas diperlukan untuk mengetahui ada tidaknya variabel independen yang memiliki kemiripan atau variabel independen dalam suatu model. Kemiripan variabel independen akan mengakibatkan korelasi yang sangat kuat. Uji multikolinearitas digunakan untuk menguji apakah dalam model regresi ditemukan ada atau tidaknya korelasi antara variabel bebas.

\section{Uji Heterokedastisitas}

Metode yang digunakan untuk mendeteksi ada tidaknya heteroskedastisitas adalah dengan menggunakan uji White. Kriteria pengambilan keputusan dalam uji White, sebagai berikut : Nilai probabilitas X2 hitung < nilai probabilitas kritis $\alpha(0.05)$, maka hipotesis yang menyatakan bahwa tidak ada heteroskedastisitas ditolak. Nilai probabilitas X2 hitung $>$ nilai probabilitas kritis $\alpha(0.05)$, maka hipotesis yang menyatakan bahwa tidak ada heteroskedastisitas diterima.

\section{Koefisien determinasi $\left(\mathbf{R}^{2)}\right.$}

Digunakan untuk mengukur pengaruh variabel independen terhadap variabel dependen. $\mathrm{R}^{2}$ bernilai antara Nol sampai dengan satu $0 \leq \mathrm{R}^{2} \leq 1$ Dapat dihitung dengan rumus sebagai berikut :

$R^{2}=\frac{\sum\left(Y^{\prime}-Y\right)}{\sum(Y i-Y)}$

Dimana:

$\mathrm{R}^{2}=$ Koefisien determinasi

$\mathrm{Y}^{\prime}=$ Determinan

$\mathrm{Y}=$ Industri pengolahan

$\mathrm{Y}_{\mathrm{i}}=$ Rata-rata industri pengolahan

\section{Uji simultan (Uji F)}

Menurut Sarwoko (2005), uji statistik F pada dasarnya menunjukkan apakah semua variabel bebas yang dimaksudkan dalam model mempunyai pengaruh secara bersama-sama (simultan) terhadap variabel terikat secara signifikan urutan uji tersebut adalah : 
Menggunakan rumus hipotesis : $\mathrm{H}_{0}: \mathrm{b}_{\mathrm{i}}=0$

$\mathrm{H}_{\mathrm{a}}: \mathrm{b}_{\mathrm{i}} \neq 0$

Tingkat signifikan yang ditentukan adalah $\alpha=5 \%$

Dengan menggunaan $\mathrm{df}=\mathrm{n}-\mathrm{k}$, sehingga

$F=\frac{R^{2} /(K-1)}{\left(1-R^{2}\right)-(\mathrm{n}-\mathrm{k})}$

Dimana:

$\mathrm{R}^{2} \quad=$ Koefisien determinasi

$\mathrm{K}=$ Jumlah variabel independen

$\mathrm{N} \quad=$ Banyaknya data/tahun

Kriteria pengujiannya adalah :

Jika $\mathrm{F}$ hitung $>\mathrm{F}$ tabel maka $\mathrm{H}_{0}$ ditolak

Jika $\mathrm{F}$ hitung $<\mathrm{F}$ tabel maka $\mathrm{H}_{0}$ diterima

Kesimpulan nya jika $\mathrm{F}$ hitung $>\mathrm{F}$ tabel maka $\mathrm{H}_{0}$ ditolak, berarti terdapat pengaruh yang signifikan antara variabel $\mathrm{x}$ terhadap variabel $\mathrm{y}$, dan sebaliknya apabila $\mathrm{F}$ hitung $<\mathrm{F}$ tabel maka $\mathrm{H}_{0}$ diterima, artinya tidak terdapat pengaruh yang signifikan terhadap variabel y.

\section{Uji parsial (uji t)}

Uji statistik t pada dasarnya menunjukkan seberapa jauh pengaruh satu variabel bebas secara individual (parsial) dalam menerangkan variasi variabel terikat. Urutan uji tersebut adalah:

Menggunakan rumus hipotesis : $\mathrm{H}_{0}: \mathrm{b}_{\mathrm{i}}=0\left(\mathrm{H}_{0}\right)$

$$
\mathrm{H}_{\mathrm{a}}: \mathrm{b}_{\mathrm{i}} \neq 0\left(\mathrm{H}_{\mathrm{a}}\right)
$$

Tingkat signifikan yang ditentukan adalah $\alpha=5 \%$

Kriteria pengujian: 1).Jika $\mathrm{t}$ hitung $>\mathrm{t}$ tabel maka $\mathrm{H}_{0}$ ditolak, 2).Jika $\mathrm{t}$ hitung $<\mathrm{t}$ tabel maka $\mathrm{H}_{0}$ diterima. Kesimpulan nya jika $\mathrm{t}$ hitung $>\mathrm{t}$ tabel maka $\mathrm{H}_{0}$ ditolak, berarti terdapat pengaruh yang signifikan antara variabel $\mathrm{x}$ terhadap variabel $\mathrm{y}$, dan sebaliknya apabila $\mathrm{t}$ hitung $<\mathrm{t}$ tabel maka $\mathrm{H}_{0}$ diterima, artinya tidak terdapat pengaruh yang signifikan terhadap variabel $\mathrm{x}$ dan $\mathrm{y}$.

\section{HASIL DAN PEMBAHASAN}

\section{Perkembangan jumlah kunjungan}

Perkembangan jumlah kunjungan wisatawan ke kebun binatang taman rimba kota jambi dari tahun 2014-2018 Titik tertinggi perkembangan kunjungan Wisatawan objek wisata Kebun Binatang Taman Rimba terjadi pada tahun 2018 sebanyak 403,919 wisatawan dibandingkan dengan tahun 2017. Titik terendah kunjungan Wisatawan objek wisata Kebun Binatang Taman Rimba terjadi pada bulan Maret sebesar 90.048 (sekitar 4,88 persen). Titik tertinggi secara keseluruhan kunjungan wisatawan objek wisata Kebun Binatang Taman Rimba terjadi pada bulan Juli dari 2014-2015 sebanyak 314.760 (sekitar 17,05 persen). Secara keseluruhan rata-rata jumlah kunjungan Wisatawan objek wisata Kebun Binatang Taman Rimba mengalami perkembangan sebanyak 8,3 persen per bulan dari bulan Januari sampai bulan Desember. 


\section{Jenis kelamin responden}

Jumlah responden jenis kelamin laki-laki sebanyak 61 responden (sekitar 38,9 persen) dan jumlah responden jenis kelamin perempuan sebanyak 96 responden (sekitar 61,1 persen). Sebagian besar responden yang ada adalah responden jenis kelamin perempuan yakni $61,1 \%$ hal tersebut dikarenakan perempuan lebih menyukai liburan dan pergi keberbagai tempat dibandingkan dengan laki-laki.

\section{Usia responden}

Umur responden pada tabel 5.2 diatas menunjukan bahwa responden yang berumur 17 - 25 tahun sebanyak 85 responden dengan presentase $54,1 \%$, responden yang berumur 26 - 34 tahun sebanyak 48 responden dengan persentase $30,6 \%$, responden yang umur 35 - 43 tahun sebanyak 20 responden dengan presentase $12,7 \%$, responden yang berumur 44 - 52 tahun sebanyak 1 responden dengan presentase $0,6 \%$. Dari hasil analisis resonden yang paling banyak berkunjung ke objek wisata Kebun Binatang Taman Rimba adalah responden yang berumur 17 - 25 tahun dan responden 26 - 34 tahun dimana pada umur tersebut umur - umurnya berkeinginan untuk berwisata.

\section{Pekerjaan responden}

Pesponden dengan pekerjaan PNS berjumlah 16 orang dengan persentase 10,2\%, responden Pelajar/Mahasiwa berjumlah 64 orang dengan presentase 40,8\%, responden yang bekerja sebagai wiraswasta berjumlah 20 orang dengan presentase $13 \%$, responden yang bekerja sebagai pegawai swasta berjumlah 15 orang dengan presentase $10 \%$, responden yang hanya bekerja sebagai ibu rumah tangga berjumlah 20 orang dengan presentase 13\%, responden yang memiliki pekerjaan dan lain - lain (serabutan, kuli, penjaga toko, sopir dll) sebanyak 22 orang dengan presentase 14\%. Dari hasil analisis diperoleh berwisata kebanyakkan dari kalangan pelajar/Mahasiswa dimana pelajar/mahasiswa haus akan pengetahuan tentang aneka fauna yang ada di seluruh dunia.

\section{Frekuensi berkunjung}

Responden yang berwisata 2 kali sebanyak 70 orang dengan presentase $44,6 \%$, responden yang berwisata 3 kali sebanyak 63 orang dengan presentase $40,1 \%$, responden yang berwisata 4 kali sebanyak 19 orang dengan presentase $12,1 \%$, dan responden yang berwisata lebih dari 4 kali sebnyak 5 orang dengan presentase $3.2 \%$. dari hasil analisis terdapat responden yang berkunjungan ulang kirasan 2 sampai 3 kali berwisata di tempat yang sama, hal tersebut dikarekan bahwa keinginan seseorang untuk berwisata ditempat yang telah dikunjungi hanya sebatas 3 kali kunjungan, jika lebih mungkin didaerah tersebut hanya itu saja objek yang ada dideaerah mereka sedangkan kebutuhan berwisata seseorang perlu dilakukan untuk mendapatkan suasana pikiran yang baru dan motivasi. Jika berwisata keluar daerah mempertimbangkan bugdet yang ada ujung - ujungnya pilih wisata yang telah sering dikunjung.

\section{Hasil analisis regresi berganda}

Model regresi berganda dalam penelitian ini digunakan utnuk menyatakan hubungan fungsional antara variabel bebas dan variabel terikat. Analisis regresi berganda dilakukan dengan menggunakan program SPSS. Berdasarkan hasil yang terdapat pada Tabel 1. 
Tabel 1. Hasil regresi

\begin{tabular}{|c|c|c|c|c|c|c|}
\hline & \multirow[t]{2}{*}{ Model } & \multicolumn{2}{|c|}{$\begin{array}{l}\text { Unstandardized } \\
\text { Coefficients }\end{array}$} & \multirow{2}{*}{$\begin{array}{c}\begin{array}{c}\text { Standardized } \\
\text { Coefficients }\end{array} \\
\text { Beta } \\
\end{array}$} & \multirow[t]{2}{*}{$\mathbf{t}$} & \multirow[t]{2}{*}{ Sig. } \\
\hline & & B & Std. Error & & & \\
\hline \multirow[t]{5}{*}{1} & (Constant) & 4,214 & ,665 & & 6,341 & , 000 \\
\hline & Daya tarik & , 169 & ,080 & , 165 & 2,123 & 035 \\
\hline & Fasilitas & , 173 & ,089 & ,157 & 1,932 & 055 \\
\hline & Aksesibilitas &,- 188 & 075 &,- 197 & $-2,514$ & 013 \\
\hline & $\begin{array}{l}\text { Kualitas } \\
\text { pelayanan }\end{array}$ &,- 226 &, 083 &,- 221 & $-2,731$ & ,007 \\
\hline
\end{tabular}

Sumber: Data diolah,2020

Berdasarkan hasil yang terdapat pada Tabel 1 maka dapat dirumuskan persamaan regresi linier berganda sebagai berikut :

$$
Y=4,214+0,169 X_{1}+0,173 X_{2}-0,188 X_{3}-0,226 X_{4}
$$

Dari persamaan tersebut dapat dijelaskah bahwa : Nilai konstanta 4,214 artinya variabel independen daya tarik, fasilitas, aksesibilitas dan kualitas pelayanan adalah 4 maka nilai kepuasan konsumen positif sebesar 4,214. B $_{1}$ sebesar 0,169 berarti variabel daya tarik ditingakatkan maka kepuasan konsumen juga akan meningkat, dengan asumsi bahwa variabel fasilitas, aksesibilitas dan kualitas pelayanan tetap. $\mathrm{B}_{2}$ sebesar 0,173 berarti variabel fasilitas ditingkatkan maka kepuasan konsumen juga akan meningkat, dengan asumsi bahwa variabel daya tarik, aksesibilitas dan kualitas pelayanan tetap. $\mathrm{B}_{3}$ sebesar -0,188 berarti variabel aksesibilitas berpengaruh negatif terhadap kepuasan konsumen. $\mathrm{B}_{4}$ sebesar -0,226 berarti variabel kualitas pelayanan berperngaruh negatif.

\section{Uji validitas}

Dilakukan dengan mengkolerasikan skor yang diperoleh dari masing - masing item dengan skor total dengan menggunakan korelasi Product Moment Perason dan hasil yang diperoleh adalah semua variabel dinyatakan valid dengan tingkat signifikan sebesar $5 \%$.

\section{Uji reabilitas}

Perbandingan anatar nilai Alpha $a_{\text {itung }} \geq 0,06$ maka item pernyataan yang digunakan bersifat reliabel, sebaliknya jika Alpha $a_{\text {itung }} \leq 0,06$ maka item dinyatakan tidak reliabel. Hasil pengujian uji reabilitas menggunakan SPSS semua variabel dinyatakan reliabel.

\section{Uji normalitas}

Uji dilakukan untuk menilai seberapa sebaran data pada sebuah kelompok data atau variabel apakah berdistribusi normal atau tidak dan dapat dilihat pada tabel Kolmogoroft- Smirnof. Dengan signifikan $\geq 0,05$, dalam peneltian ini kelompok data dengan tingkat 0,200 yang artinya lebih besar dari 0,05 dan dapat disimpulkan bahwa variabel - variabel dalam penelitian ini berdistribusi normal.

\section{Uji heterokedastisitas}

Metode yang digunakan untuk mendeteksi ada tidaknya heterkedastisitas dengan menggunakan Uji White. Uji heterkedastisitas tingkat signifikansi $\geq 0,05$ tidak terjadi heteroskedastisitas dan apabila tingkat signifikansi $\leq 0,05$ maka terjadi 
heteroskedastisitas. Pada tabel variabel Daya tarik $\left(\mathrm{X}_{1}\right)$, Fasilitas $\left(\mathrm{X}_{2}\right)$, Aksesibilitas $\left(\mathrm{X}_{3}\right)$, Kualitas Pelayanan $\left(\mathrm{X}_{4}\right)$ tidak terjadi heteroskedastisitas.

\section{Uji multikolinearitas}

Variance infllation factor (VIF) Tolerance dapat digunakan untuk mendeteksi adanya multikolinearitas bila nilai VIF $<10$. Jadi tidak ada multikolinearitas . Jika dilihat dari hasil output pada nilai tolerance variabel daya tarik, fasilitas, aksesibilitas dan kualitas pelayanan menunjukkan bahwa tolerance mendekati 1 maka bisa dikatakan model regresi bebas dari multikolinearitas.

\section{Uji simultan (Uji F)}

Hasil daya tarik $\left(\mathrm{X}_{1}\right)$, fasilitas $\left(\mathrm{X}_{2}\right)$, aksesibilitas $\left(\mathrm{X}_{3}\right)$, kualitas pelayanan $\left(\mathrm{X}_{4}\right)$ terhadap $\mathrm{Y}$ menghasilkan $\mathrm{F}_{\text {hitung }}$ 7,593 pada signifikansi 0,00 yang berati bahwa variabel daya tarik, fasilitas, aksesibilitas dan kualitas pelayanan sama - sama berpengaruh terhadap kepuasan konsumen.

\section{Uji parsial (Uji t)}

Uji t-statistik variabel daya tarik wisata $\left(X_{1}\right)$ menghasilkan thitung $(3,702)$ pada signifikansi $(0,008)$ maka $\mathrm{H}_{0}$ diterima dan Ha ditolak terhadap kepuasan konsumen. Variabel fasilitas wisata $\left(\mathrm{X}_{2}\right)$ menghasilkan thitung $(2,828)$ pada signifikansi $(0,005)$ maka $\mathrm{H}_{0}$ ditolak dan Ha diterima jadi $\mathrm{X}_{2}$ berpengaruh positif terhadap kepuasan konsumen.

Uji t-statistik variabel aksesibilitas $\left(\mathrm{X}_{3}\right)$ menghasilkan thitung $(-3,628)$ pada signifikansi $(0,00)$ maka $\mathrm{H}_{0}$ ditolak dan $\mathrm{Ha}$ diterima jadi $\mathrm{X}_{3}$ berpengaruh negatif terhadap kepuasan konsumen. Uji t-statistik variabel kualitas pelayanan $\left(\mathrm{X}_{4}\right)$ menghasilkan thitung $(-3,961)$ pada signifikansi $(0,00)$ maka $\mathrm{H}_{0}$ ditolak dan Ha diterima jadi $\mathrm{X}_{4}$ berpengaruh negatif terhadap kepuasan konsumen.

\section{Koefisien determinasi $\left(\mathbf{R}^{2)}\right.$}

Koefisien determinasi $\mathrm{R}^{2}$ sebesar 0,567 artinya 56,7\% kepuasan konsumen dapat dijelaskan oleh variabel daya tarik, fasilitas, aksesibilitas dan kualitas pelayanan, sedangkan 43,8\% kepuasan konsumen dipengaruhi oleh variabel lain yang tidak dijelaskan dalam penelitian ini.

\section{KESIMPULAN DAN SARAN}

\section{Kesimpulan}

Berdasarkan hasil analisis data penelitian tentang pengaruh minat kunjungan ulang wisatawan penulis mengambil kesimpulan sebagai berikut: (1) Berdasarkan hasil uji validitas semua variabel daya tarik, fasilitas, aksesibilitas, kualitas pelayanan dan minat kunjungan ulang dinyatakan valid. (2) Berdasarkan hasil uji simultan F dapat disimpulkan bahwa daya tarik, fasilitas, aksesibilitas, kualitas pelayanan bersama sama berpengaruh terhadap minat kunjungan ulang. (3) Daya tarik wisata dan fasilitas wisata berpengaruh positif terhadap minat kunjungan ulang. (4) Aksesibilitas dan kualitas pelayanan berpengaruh negatif.

\section{Saran}

Kebun binatang merupakan salah satu wahana hiburan umum yang harus ditingkatkan dan dikelolah denganlebih baik dari waktu ke waktu. Yang harus ditingatkan lagi bagi khusus untuk kebun binatang Taman Rimba adalah : (1) Kawasan harus diperluas sehingga pengujung betah berlama - lama menikmati liburan tanpa harus berdesak - desakan apalagi dengan cuaca Jambi yang panas.(2) Kandang - 
kandang harus lebih diperhatikan kebersihannya dan keluasan tempat sehingga hewan hewan bebas bergerak. (3) Terlebih lagi kepada hewan seperti singa dan harimau yang terlihat kurus yang kurang aktif yang harus benar - benar dijaga karena jumlah populasi meraka yang tidak banyak lagi tersedia dibumi. (4) Jalur keluar masuk pengujung harus dibedakan sehingga tidak terjadi desak- desakan atar pengujung lain. (5) Tempat antrian tiket yang tidak memadai seperti pengujung berpanas- pasanan saat membeli tiket. (6) Perbanyak wahana hiburan menarik (7) Sediakan tempat parkir yang berteduh.

\section{DAFTAR PUSTAKA}

Furchan, A. (2004). Pengantar penelitian dalam pendidikan. Pustaka Pelajar: Yogyakarta:

Gaffat, Vanessa. (2007). Marketing publik relation. Alfabeta: Bandung.

Ghozali, Imam. (2013). Aplikasi analisis multivariate dengan program SPSS. Edisi Ketujuh. Semarang: Universitas Diponegoro: Semarang

Gujarati, Damodar. (2003). Ekonometri dasar. Terjemahan: Sumarno Zain, Erlangga: Jakarta

J Junaidi, A Amril, JK Edi, M Ridwansyah, D Hastuti, S Aminah. (2019). Arahan zonasi pada pengembangan agrowisata berbasis community based tourism Desa Renah Alai, Jurnal Inovasi, Teknologi dan Dharma Bagi Masyarakat, 1 (1), 2936

James dan Spillane, S.J. (1994). Pariwisata Indonesia siasat ekonomi dan rekaysa kebudayaan. Kanisius: Yogyakarta

Pendit, Nyoman S. (1994). Ilmu pariwisata sebuah pengantar perdana. PT. Pradnya Paramita: Jakarta

Rozak, B. R. (2012). Kualitas daya tarik wisata, kepuasan wisatawan dan niat kunjungan kembali wisatawan mancanegara di Jawa Tengah. Dinamika Kepariwisataan Vol. XI, No. 2.

S Amin, D Hastuti.(2020). Analysis of the local potential attraction in Sipin Lake Jambi City. Talent Development \& Excellence 12 (1), 2315-2332

Safri, Muhammad. (2003). Dampak pariwisata alam taman nasional kerinci seblat terhadap ekonomi masyarakat sekitar dan wilayah Kabupaten Kerinci Provinsi Jambi. Riset. Universitas IPB. Bogor: Bogor

Spillane, James J. (1994). Pariwisata Indonesia siasat ekonomi dan rekayasa kebudayaan. Kanisius: Yogyakarta

Sugiyono. (2004). Statistika untuk penelitian. Alfabeta: Bandung

Sugiyono. (2011). Metode penelitian pendidikan (pendekatan kuantitatif, kualitatif, dan $R \& D)$. Alfabeta: Bandung

Suwantoro, Gamal. (2004). Dasar-dasar pariwisata. Andi: Yogyakarta 